\title{
Alternative scenarios of the demographic development of rural Russia: analysis and forecast
}

\section{Escenarios alternativos para el desarrollo demográfico de la Rusia rural: análisis y pronóstico}

\author{
Tatiana Viktorovna-Blinova and Svetlana Gennadievna-Bylina \\ Institute of Agrarian Problems of the Russian Academy of Sciences, \\ Saratov, Russian Federation
}

\begin{abstract}
The purpose of the study is to discuss the alternative scenarios of the demographic development of rural Russia. The Covid-19 coronavirus pandemic has changed the demographic situation in Russia: mortality and natural population decline increased, while the birth rate decreased. Based on the cohort-component method, we projected the rural population size and age structure for the period 2024-2049. Six alternative scenarios were developed: three with zero migration (without taking into account the impact of migration changes on the rural population) and three with migration. Therefore, the migration outflow coefficient was included in the three forecasting scenarios. However, the inflow of some urban population to the countryside is not ruled out. The results show that the population of rural Russia will decrease from 37.3 million (2019) to 29.6-33.1 million people (2049). The age structure of the population will change, the demographic aging of rural areas will continue.
\end{abstract}

Keywords: Population; Forecast; Scenarios; Rural Russia.

\section{Resumen}

El propósito del estudio es presentar escenarios alternativos para el desarrollo demográfico de la población rural de Rusia. La pandemia del Covid-19 ha cambiado la situación demográfica en Rusia: la mortalidad y el declive natural de la población han aumentado y la tasa de natalidad ha disminuido. Hemos proyectado la población rural para el periodo 2024-2049 basándonos en el método de componentes de cohortes. Hemos construido seis escenarios alternativos, de los cuales tres asumen migración cero y tres tienen en cuenta el impacto de los cambios migratorios en la dinámica de la población rural. Por lo tanto, el coeficiente de emigración se ha incluido en las tareas de pronóstico en tres de los escenarios. Sin embargo, no descartamos la inmigración de parte de la población urbana a zonas rurales. Los resultados del pronóstico concluyen que la población rural de Rusia disminuirá de 37.3 millones (2019) a 29.6-33.1 millones de personas (2049). La estructura de edad de la población cambiará y el envejecimiento demográfico de las zonas rurales continuará.

Palabras clave: Población, Pronóstico, Escenarios, Rural Rusia. 


\section{INTRODUCTION}

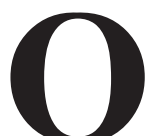

ver the last few decades, the world has experienced significant demographic changes, such as decrease in fertility, increase in life expectancy, strong international migration and, as a result, the transformation of the age composition of the population (Denisenko, Kozliov, 2018: 40). A decrease in the birth rate and a decrease in the number of children in a family is a global trend, also present in Russia. Currently, the total fertility rate (TFR) in Germany, the Netherlands, Norway is 1.6, in Canada, Austria, Hungary -1.5 , Greece, Portugal, Japan -1.4, Spain, Italy -1.3 , which is below the level of replacement of generations (Rosstat, 2019: 249), in Russia-1.505 (2020). ${ }^{1}$ The formation of the trend towards low and lowest-low fertility is influenced by many factors, including not only a change in the structure of family values and poor motivation of women to give birth to a second or third child, but also the state of the economy, labor market, level and quality of life of families, epidemiological situation. The continuing fertility decline in Russia necessitates a study of socio-economic factors influencing this trend as well as the relations between these factors (Trynov et al, 2020: 807). The authors identified differences

in the influence of individual variables on the dynamics of fertility rates for the first child and subsequent children..., the influence of real monetary income on the birth order rates is gradually decreasing, while the influence of the unemployment rate, reserves-to-production ratio, and marriage rate is multidirectional (Trynov et al., 2020: 807).

Current problems of low and lowest-low fertility are discussed by many authors (Anderson and Kohler, 2015; Frejka, 2017; Zeman et al., 2018; Seltzer, 2019). The causes of low fertility are gender inequality, high spending on children's education, women's desire for economic independence, lack of necessary conditions for the implementation of reproductive intentions. A study of the relationship between household investment in children's education and low birth rates allowed the authors to conclude that such institutions as the higher education system and the labor market affect the number of children in a family (Tan et al., 2016). The authors showed that the high costs of educating children and parents' desire for their children to get a diploma from a prestigious university, and later a good job,

${ }_{1}^{1}$ The total fertility rate. Federal State Statistics Service, available at: https://gks.ru/bgd/regl/ b20_111/Main.htm 
put pressure on the decision on the number of children in the family (Tan et al., 2016). An important role is played by institutional conditions that encourage women to combine work and motherhood. In those economically developed countries where institutional conditions have been created for combining motherhood and professional employment, birth rate is closer to generational replacement than in other countries, where birth rate remains low (Rindfuss et al., 2016). In many countries, social policy is currently aimed at a gender-equal division of childcare and economic responsibility (Duvander et al., 2020). Russia has a social policy aimed at supporting families with children, however, the birth rate remains low.

Demographic aging of the population is one of the irreversible consequences of low fertility. Aging, which occurs in different countries at different speeds, has implications for the national pension system and the development of health care for older people (Alho et al., 2006).

Population ageing is one of the most important challenges for national economies in the current century... all regions of the world during the 21 st century will face the problem of an increasing proportion of representatives of older age cohorts (Petrosian et al., 2019: 45).

In rural Russia the share of people over working age increased from 21.6 per cent (2005) to 26.8 per cent (2019), in 2020, it dropped to 25.9 per cent as a result of an increase in the retirement age (Rosstat, 2019, 2020). In rural Russia demographic aging has affected the regions to varying degrees, the proportion of people over working age in the structure of the rural population ranges from 16.7 per cent in the North Caucasus to 29.6 per cent in the Central Federal District (Rosstat, 2019). Gender asymmetry and feminization of the process of demographic aging were identified in rural areas of Russia (Blinova, 2021: 76).

Rural-urban migration intensifies the demographic aging of rural areas, as the majority of people moving to cities are usually from a younger age group. The outflow of young people from rural areas to cities has two peaks, firstly, at the age of leaving school, and secondly, at the age of starting a professional career (Mkrtchyan, 2019). At the end of 2019, the internal migration of the rural population is negative. At the same time, there is an influx of migrants to the suburban countryside due to intraregional migration from the territories of the "periphery" (Mkrtchyan, 2019: 45). External migration is represented by residents of Armenia, Belarus, Kazakhstan, Georgia and other countries. Covid-19 pandemic had a negative impact on migration flows. Quarantine measures in connection with the 
coronavirus pandemic have been accompanied by the closure of cross-border communications and restrictions on the activities of enterprises in most sectors of the economy (Denisenko, Mukomel, 2020). In the context of the coronavirus pandemic and the adoption of restrictive measures, the migration population growth has significantly decreased from 285103 (2019) to 106496 people in Russia (Rosstat, 2020).

The Covid-19 coronavirus pandemic has changed the demographic situation in the world. Russian Federation has confirmed 5.7 million cases of coronavirus, 5.1 million people have recovered and 139.3 thousand people died. ${ }^{2}$ According to Rosstat, the population of Russian Federation as of January 1, 2021 amounted to $146{ }^{\prime} 238,185$ people, which is a decrease of more than 510 thousand people from $2020 .^{3}$ The scale of the decline in the population of Russia turned out to be the highest over the past 15 years. Assessing the impact of the Covid-19 pandemic on demographic change is currently difficult as the pandemic is not over yet. Researchers limit themselves to studying the directions of the influence of the pandemic and restrictive measures on fertility, mortality, and migration. The demographic risks that can negatively affect the demographic situation, increasing mortality and natural population decline, have been identified, not only during the pandemic, but also after the abolition of the self-isolation regime, as delayed negative consequences (Kulkova, 2020). During the Covid-19 pandemic, the mortality of urban and rural population has increased in all regions of Russia. So, in 2020, the number of death reached 2.124 million, which is almost 18 per cent higher than in the last year, the crude death rate increased to 14.5 (deaths per 1,000 population) in 2020, reaching record levels over the past decade (12.3 in 2019). ${ }^{4}$ In addition to coronavirus infection, an increase in mortality can be facilitated by both restrictions in the provision of routine medical care to patients and complications caused by Covid-19 (Gavrilova, Gavrilov, 2020). The minimum increase in the number of deaths was noted in Buryatia, Adygea and Sevastopol, where losses increased by 6.8, 7.3, 7.4 per cent, respectively, the maximum - in the national republics of the North Caucasus by 29.1 per cent in Ingushetia, 34 per cent in Dagestan, 44.5 per cent in Chechnya (Ryazantsev et al., 2021: 12). As a result of the excessive mortality in 2020, against the background of the pandemic, the long-term positive trend of life expectancy growth in Russia was interrupted, which persisted even during the crisis

\footnotetext{
2 https://www.rbc.ru/society/06/07/2021/5e2fe9459a79479d102bada6?from=from_main_3

3 https://rosstat.gov.ru/folder/12781

4 https://www.rbc.ru/economics/08/02/2021/602132e19a7947073f7ddeb5?from=from_main_4
} 
periods of 2008-2009 and after 2014 (Ryazantsev et al., 2021: 8). Thus, the Covid-19 pandemic is a new factor of depopulation in Russia.

These changes were taken into account when developing a scenario forecast for 2024-2049. Researchers emphasize that for Russia with an unevenly populated vast territory rich in natural resources, the problem of demographic development is more important and relevant than for other states of the world (Rybakovsky and Tayunova, 2018: 59). Assessment of the demographic changes is especially important for development and implementation of a program for sustainable development of rural areas. At the same time Rosstat does not publish a forecast of the size and structure of the rural population. The development of forecast options is based on a description of possible scenarios for changing the number and structure of the population. This takes into account factors that can affect the change in demographic development in the specified period. The fundamental assumptions in the description of the scenarios are based on an analysis of trends in fertility, mortality, and migration, which must be taken into account when developing the forecast. We assume that the birth rate decrease in the short term will be followed by the compensatory growth, after which a decline is possible. For certain socio-demographic groups of the population, the role and significance of family values will increase, and they will be oriented towards the medium or large model of the family. Other social groups that believe that "it is better to survive alone" would prefer a child-free or childless family model. Depending on the dominance in the regional communities of one or the other type of family, the demographic situation in the future will change.

Demographic forecast based on certain theoretical assumptions and deep empirical analysis is of great applied value (Alho and Spencer, 2005). The forecasting of the population of Russia, based on the principle of alternative possibilities, is carried out by Rosstat in three versions: low, medium and high. According to this forecast, the population of the Russian Federation by 2036 is expected to be 138.1-153.2 million people, and the share of the working-age population will be 54.7-52.8 per cent (Rosstat, 2019). The reduction in the rural population is one of the restrictions on the development of the agrarian economy of Russia and ensuring the country's food security, which actualizes the task of assessing demographic changes in the medium term. It is important to note that depopulation in rural areas as a result of decline in the birth rates, rise in mortality associated with a population ageing, and migration outflow of the rural population is typical 
for many countries and was studied in detail by the authors (Johnson and Lichter, 2019).

The purpose of the study is to construct a demographic forecast and develop alternative scenarios of changes in the rural population by 2049 . Research objectives are to (i) study the trends in the demographic development of rural areas; (ii) describe the possible scenario of the demographic forecast; (iii) develop a medium-term forecast of the rural population; (iv) perform a comparative analysis of rural population dynamics in different scenarios of the demographic forecast. The information base of the study is based on the statistics from the Federal State Statistic Service (Rosstat).

\section{Materials AND MethodS}

Estimates of the current and projected population size are carried out using certain methods and models (Alho et al., 2006; Liu et al., 2016; Ordorica et al., 2019). To develop a medium-term forecast of the rural population, we used the component method based on the equation of demographic balance. This method has been tested previously (Blinova, Bylina, 2014). Analysis of certain changes in fertility, mortality and migration made it possible to model extrapolation dependencies and calculate age-specific birth and death rates for men, women, and children under one year of age and to construct demographic forecast scenarios. The probability is calculated for a woman who at the moment of time $t$ is in the age group $m$ to give birth to a child over a period of time $(t, t+1)$. Based on the age-specific mortality rates, the survival rate was calculated - the probability for a person who was in a certain age group at time $\mathrm{t}$ to die before time $t+1$. Predictive calculations are carried out according to the program developed in the Mathcad 14.0 system and designed to predict the size and structure of the population for a period of 5,10 and 15 years. The number of age groups is 18 in accordance with the age and sex structure of the population presented in the data of Rosstat.

The demographic forecast is based on a scenario approach, that is widely used in population forecasting (Goujon et al., 2020). Cafaro and Dérer presented "new population projections up to 2100 for the countries of the European Union and for the EU as a whole under a wide range of fertility and migration scenarios" (2019: 171). Six alternative scenarios of growth of the rural population (2024-2049) have been presented. The first three scenarios assume zero migration, and the other three take into account the impact of rural-urban migration on changes in rural population. The "low" scenario suggests that age-specific fertility and mortality rates 
remain unchanged throughout the forecast period. The medium scenario was developed on the basis of the expected increase in the birth rate, while the prevailing trends in the mortality rates of the rural population remain. The "high" scenario is focused on achieving the goals set in the National Project "Demography", which implies an increase in the birth rate and a reduction in mortality and is notable for its low probability.

The first three scenarios were calculated with zero migration. At the same time, the migration outflow of the rural population into the city continues, due to both the process of urbanization, and the lack of jobs and low wages in rural areas. At the next stage of forecasting, the migration outflow coefficient was included in the tasks of modeling the rural population and the same scenarios were developed taking into account rural-urban migration. The research is based on Rosstat data (Rosstat, 2002; Rosstat, 2007; Rosstat, 2012; Rosstat, 2015; Rosstat, 2017; Rosstat, 2019; Rosstat, 2020). The calculations were performed using Mathcad 14.0. Separately, we analyze the demographic consequences of the world-wide pandemic of the coronavirus Covid-19. Despite the situation of demographic uncertainty, we expect a decline in fertility and an increase in mortality as a result of the pandemic. Possible negative consequences of the Covid-19 pandemic are taken into account in the low scenario of demographic development. The cyclical economic recession 2020-2021 is likely to reinforce the negative demographic changes. At the same time, we expect a compensatory increase in the birth rate, as well as a reduction in mortality as a result of the implementation of a set of government measures aimed at supporting the population.

\section{RESULTS AND DISCUSSION}

\section{Recent demographic trends and population age structure in Rural Russia}

Population age structure. The structure of the rural population of the Russian Federation by age and gender, prevailing at the beginning of the forecast period, will have the strongest influence on the prospective demographic dynamics. Figure 1 shows the structure of the rural population by 18 age groups as of January 2019 (Rosstat, 2019).

Figure 1 shows a "demographic failure" in the number of people aged 15-19 years and 20-24 years, which will negatively affect the age structure of the rural population of working age in the long term. In addition, in the next 5-10 years, numerous cohorts of the current 50-54 and 55-60 


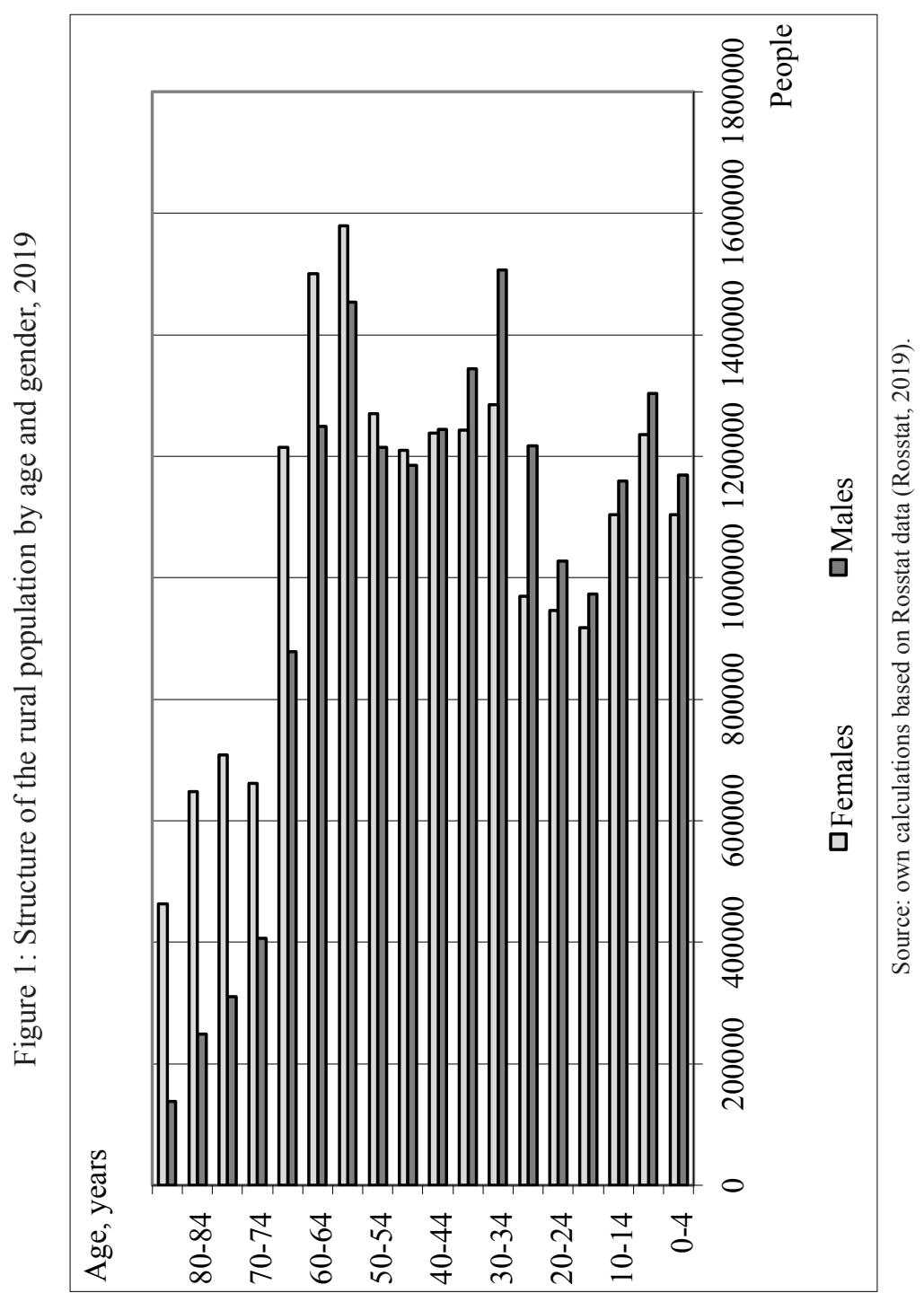


year-olds will retire, taking into account the increase in the retirement age. At the beginning of 2019, those older age groups had 715 thousand more people than the replacement group aged 5-14.

A reduction in the number of people of working age in the structure of the rural population is inevitable. Attention should be paid to the reduction in the number of women of active reproductive age, which is one of the factors reducing the number of births. In the next five years, the size of this group will decrease by 105 thousand people, excluding mortality rates. At the same time, an increase in the rural population of older ages with high mortality rates is inevitable. It is necessary to take into account the increased mortality risks of various population groups during the Covid-19 coronavirus pandemic.

Thus, the age structure of the rural population and the current epidemiological situation will contribute to a decrease in the birth rate and an increase in the mortality rate of the rural population, especially the older age groups, which can increase the extent of natural decline.

Fertility in the rural areas. In 1999, the total birth rate in Russia reached its minimum level (1.157), after which it started growing cyclically to 1.777 (2015). The highest level of the total birth rate in rural areas was 2.318 (2014) (Rosstat, 2017: 45). In 2007, the Concept of the Demographic Policy of the Russian Federation for the period up to 2025 was approved. It is aimed at improving the conditions for the reproduction of the Russian population and stabilizing its population (The Concept, 2007). Additional measures included maternal (family) capital payments, subject to the birth of second and subsequent children. Positive trends in the demographic development of both rural and urban areas in these years were manifested in an increase in the birth rate, a decrease in mortality, and a decrease in the scale of depopulation. In 2013-2015, a positive natural growth of the Russian population and the cessation of the natural decline in the rural population (2013) were noted. An important achievement of these years is that the total fertility rate in real generations of women have stopped declining (Rybakovsky and Tayunova, 2017: 56).

Growth in the birth rate at this stage was facilitated, firstly, by an increase in the number of potential mothers, which continued in rural areas up to 2006, and secondly, the birth of second, (third) children under the influence of active demographic policies. The upward trend in the birth rate of the rural population, observed since 2000, interrupted in 2005-2006 and resumed in 2007, was replaced by a downward trend starting in 2015 (Figure 2 ). The figure shows the total fertility rate (TFR) of the Russian population, 


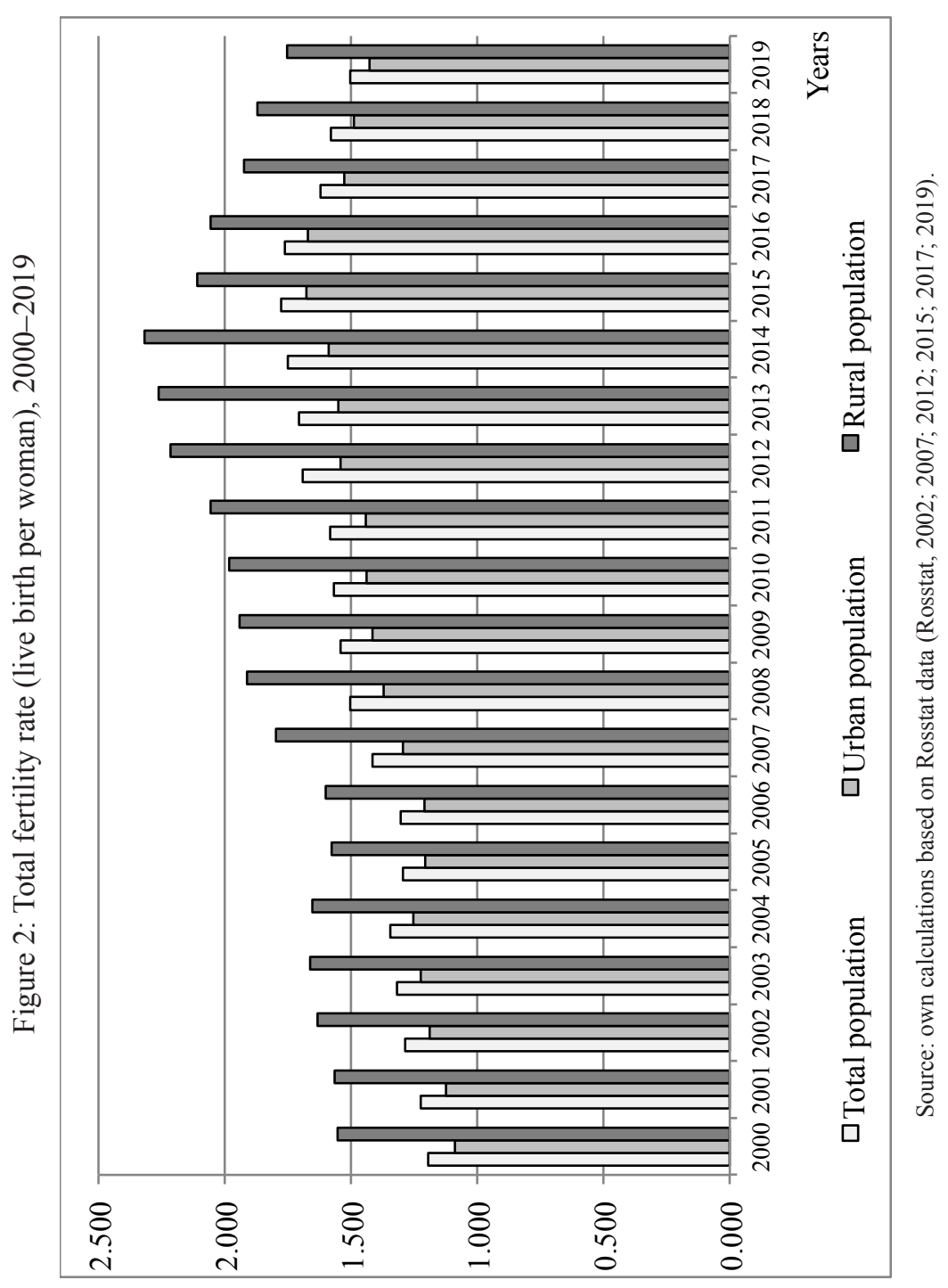


including urban and rural areas. In 2000-2010 and 2016-2018, TFR values in rural areas were below the level of simple generational substitution.

In 2012-2015, the values of the total fertility rate of the rural population were at the level of expanded reproduction. An increase of the total fertility rate from 1.554 to 2.318 in 2000-2014, was followed by a cyclical decline to 1.870 in 2018 . It is expected to continue declining in the near future. The values of the total fertility rate of the urban population in 2000-2007 remained at an extremely low level (less than 1.3), and in 2008-2018 it was below the level of simple reproduction. It should be noted that rural fertility index during the researched period never fell to an extremely low level, in contrast to the urban one. We assume that in the forecast period rural fertility index will be lower than the level of simple reproduction, but it will not go down to an extremely low level.

Additional difficulties in predictive fertility modeling arise in connection with the prevailing epidemiological situation associated with the coronavirus Covid-19 pandemic. We hypothesized an inevitable short-term decline in fertility, possibly to a lowest-low. However, after the stabilization of the situation, a compensatory short-term increase in the birth rate is predicted. We assume that the medium-term trend in the fertility rate remains downward. Studies show that the current decline in fertility in Russia is cyclical in nature. Exogenous factors such as socio-economic instability caused by the coronavirus pandemic may increase the decline in fertility, but are not its fundamental cause.

The highest risks of fertility decline are in the age groups of 20-34 years. An important reason is the decrease in the number of women of active reproductive age. Currently, there are a few cohorts from 15 to 29 years old in active reproductive age. We can assume an increase in the birth rate in 15-19 year-old age group in the next five years and a decrease in this indicator in 30-34 year-old age group of rural women. Due to changes in the age-specific fertility model, when an increasing share of births is shifting to older women (delayed births of the first child), fertility rate may increase at older ages. It depends on an increase in the number of women of older age groups, and on public measures aimed at stimulating the birth of second and subsequent children.

Mortality in rural areas. In the structure of the causes of mortality of the rural population, diseases of the circulatory system are in the first place, neoplasms are in the second, followed by the external causes of death. (Rosstat, 2019). Among the causes of death of rural women, unlike men, in the third place are diseases of the digestive system. In 2005-2018 there 


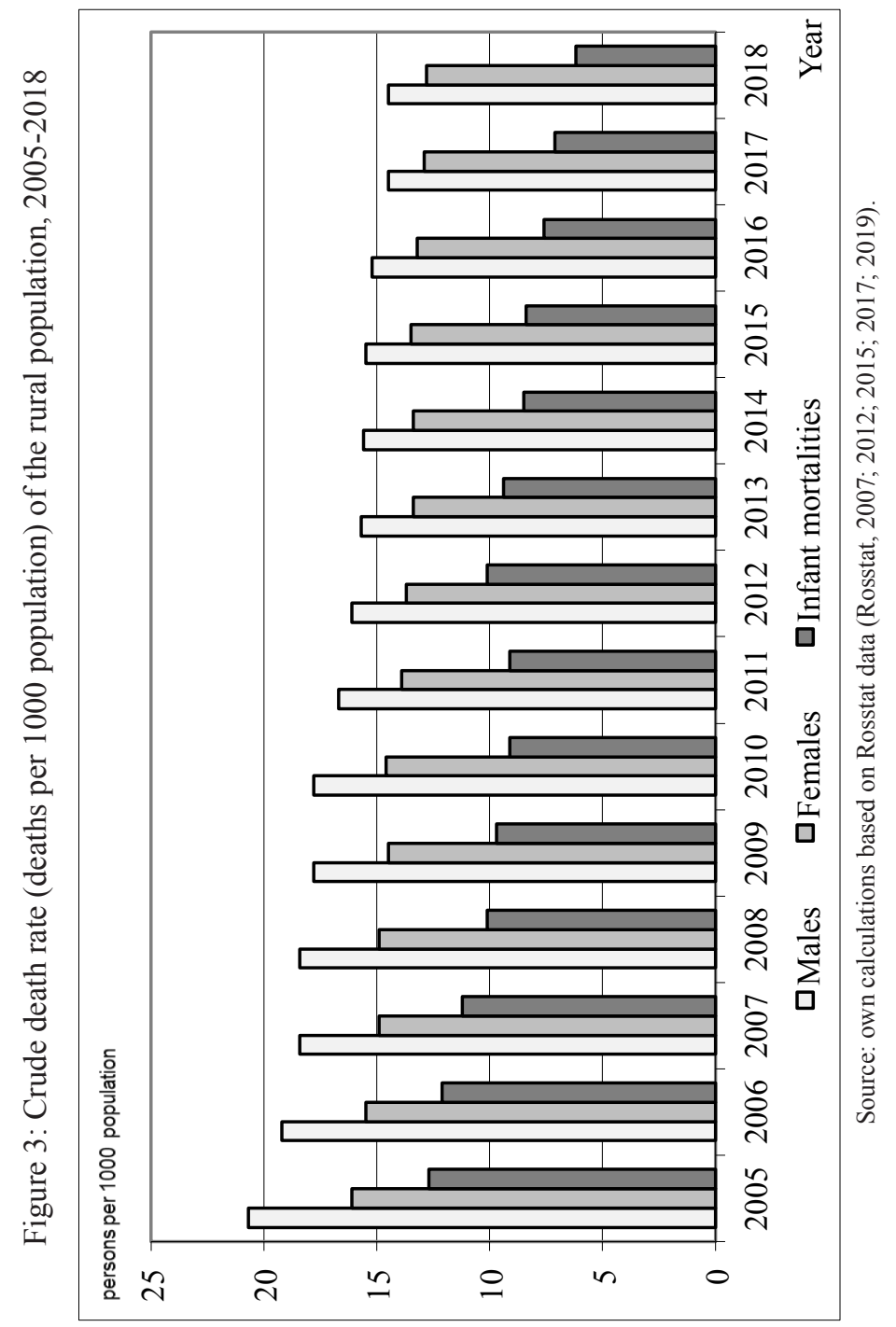


was a decrease in the overall mortality rates of rural men, women and children up to one year (Figure 3).

Active demographic and social policies of the state aimed at increasing life expectancy had a positive impact on reducing mortality in the rural population. In 2005-2018 the mortality rates of rural men decreased by 30 per cent, of women - by 20.5 per cent, the mortality rates of infants decreased by 50 per cent (Figure 3 ).

However, it should be noted that in 2017-2018 mortality rates of rural men stopped at the level of 14.5 people per 1000 population, of rural women $-12.8-12.9$ people per 1000 population. This fact is partially explained by an increase in the share of older people in the structure of the rural population and by an increase in life expectancy from 63.45 years (2005) to 71.67 years (2018). The mortality of the rural population of working age, especially men, has decreased most significantly. The overall mortality rates of rural able-bodied men for the period under review decreased by 43.1 per cent, of women - by 34.2 per cent.

International statistics show that women in economically developed countries live longer than men (United Nations, 2019). In Russia the gender differences in mortality in Russia are among the most pronounced in the world. At the same time, in the context of a decrease in the mortality rate in the country, the gender gap is naturally narrowing (Medalia and Chang, 2011: 371-389). In rural Russia, the highest gap in the life expectancy of women and men was 13.84 years (2005), by 2016 the gender gap in life expectancy fell to 10.7 , by $2018-10.2$ years, remaining still significant despite an annual decrease. According to the analysis, the rate reduction in mortality in different socio-demographic groups of the rural population is different. Thus, analysis of the dynamics of mortality rates in the rural population of the Russian Federation suggests a decrease in mortality among infants, as well as among people of working age, while an increase in mortality rates in the group of adults 65 years and older is expected. Consequently, in the short term, a further significant decrease in the general mortality rates of the rural population is unlikely.

Rural-urban migration. The resettlement of part of the rural population to cities reflects both the regular process of urbanization and the excessive outflow of young people and qualified personnel from the rural areas due to poor development of social infrastructure, lack of jobs with high wages, limited options for choosing the scope of employment and high rural-urban differences. The migration growth rate of the rural population during the period under review is negative. The outflow of residents from rural areas 
to cities depends on a set of economic, social, demographic, environmental factors and enhances the negative impact of natural population decline.

The lowest migration balance was recorded in 2016, a relatively low one in 2007-2009 and 2015-2017. A sharp surge in the outflow of population from rural areas was in 2010 and was caused by economic losses due to heat waves and fires, which caused significant damage to residents of the countryside. In 2014-2016 a decrease in the migration activity of the rural population was observed, and in 2016 the lowest level of outflow of the population from the countryside was recorded for the entire considered period of time -9.7 persons per 10,000 population. In 2018, the scale of rural-urban migration increased again. The main reason for the departure of rural youth to cities is starting their education in the institutions of higher and secondary vocational education. However, after graduation, graduates of universities and colleges do not want to return to rural areas due to, the lack of jobs and low wages in rural areas, low living standards, a huge social gap between cities and villages, and lack of opportunities. Qualified personnel are leaving rural areas for the same reasons. Analysis of migration activity by gender and age (Figure 4) shows that the first "peak" of the outflow of the population from rural areas occurs at the age of 15-19 years, which is associated with the completion of general or complete secondary education. The second "peak" of the outflow occurs in 25-29 years. In this case, moving to cities is associated with employment or a job search.

A comparative analysis of gender differences indicates a higher migration activity of rural women compared to rural men. It should be emphasized that the maximum outflow of rural women falls on the age of 25-29 years. In 2018, 25- 34 years old women left the rural areas 3.3 times more than men.

The return of youth to the rural areas is observed between the ages of 20 and 24 years. It is associated with the graduation from secondary vocational or higher educational institution, as well as the return of young men from active service in the Armed Forces of the Russian Federation. In addition, over 35 year old men and over 40 year old women return to rural areas, or choose it as their new place of residence.

The identified features of the birth rate, mortality and migration outflow of the rural population were taken into account when developing alternative scenarios of demographic development of rural areas of Russia. 
Alternative scenarios of the demographic development of rural Russia: analysis and forecast / T. V. BLINOVA and S. G. BYLINA

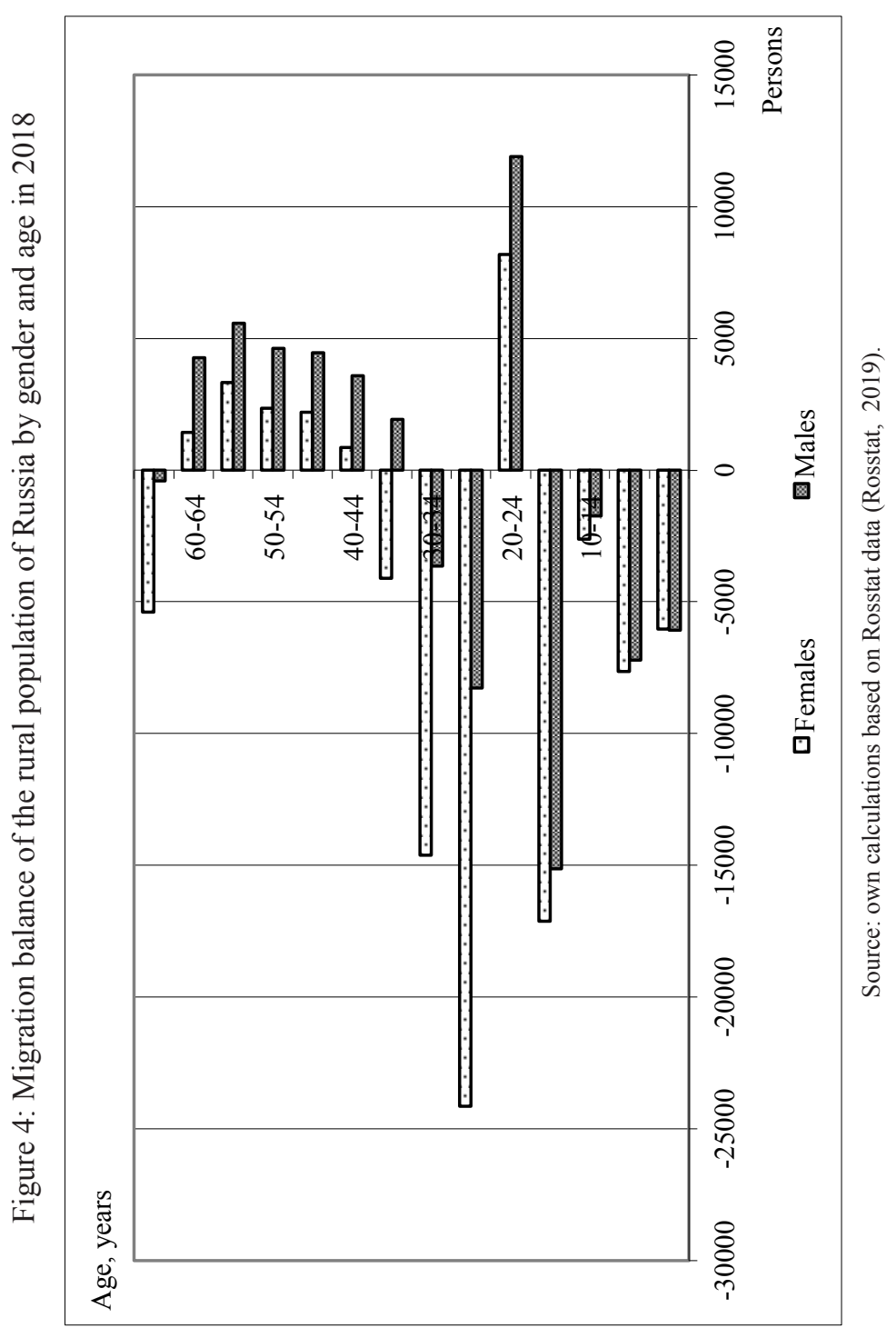




\section{Forecast of the rural population: alternative scenarios}

The alternative scenarios of changes in the population size and age structure, were modeled using the component method based on the equation of demographic balance.

The initial input were the number, gender and age structure of the rural population of the Russian Federation as of January 1, 2019, birth rates by mother's age and age-specific mortality rates for 2018. The indicated scenarios (low, medium and high) were calculated both with zero migration and taking into account the scale of migration outflow from the rural areas. In the forecast calculations we used the coefficient of migration growth of the rural population, observed in 2018 at the level of 18.6 people per 10,000 population. The values of age-specific fertility and mortality rates changed depending on the forecast scenario in 2028 , and then they were fixed at the achieved level. Assessment of projected shifts in fertility and mortality rates was performed for each forecast scenario. Forecast calculations were performed for the period up to 2049 in increments of five years. As a result of predictive modeling, the population sizes for the 18 age and gender groups of the rural population of the Russian Federation were obtained, as well as the number of men, women and the rural population as a whole. The results of scenario forecasting of changes in the rural population of the Russian Federation are presented in Figure 5. According to Fig. 5, the rural population by January 1, 2049 is projected to reduce to 31.3-35.0 million people with zero rural-urban migration and to 29.5-33.1 million people taking into account the migration outflow of the rural population. Thus, the rural population in 2049 may range from 79.2 per cent to 93.8 per cent of the 2019 level. Figure 5 clearly shows that the decreasing trend in the size of rural population of Russia in the medium term will continue according to all considered scenarios of rural demographic development.

The largest reduction in the rural population is assumed according to the low scenario of the demographic development of rural areas. By 2049, it will reach six million people excluding migration and 7.8 million people with the migration level of 2018. The average scenario of rural demographic development suggests the possibility of fertility growth in certain age cohorts of women under the influence of state demographic and social policies and allows extrapolation modeling of mortality reduction. Under these conditions, by 2049 , a decrease in the rural population will reach 3.9 million people with zero migration and 5.8 million people taking into account the migration outflow of the rural population. 
Alternative scenarios of the demographic development of rural Russia: analysis and forecesst / T. V. BLLNOVA and S. G. BYLINA

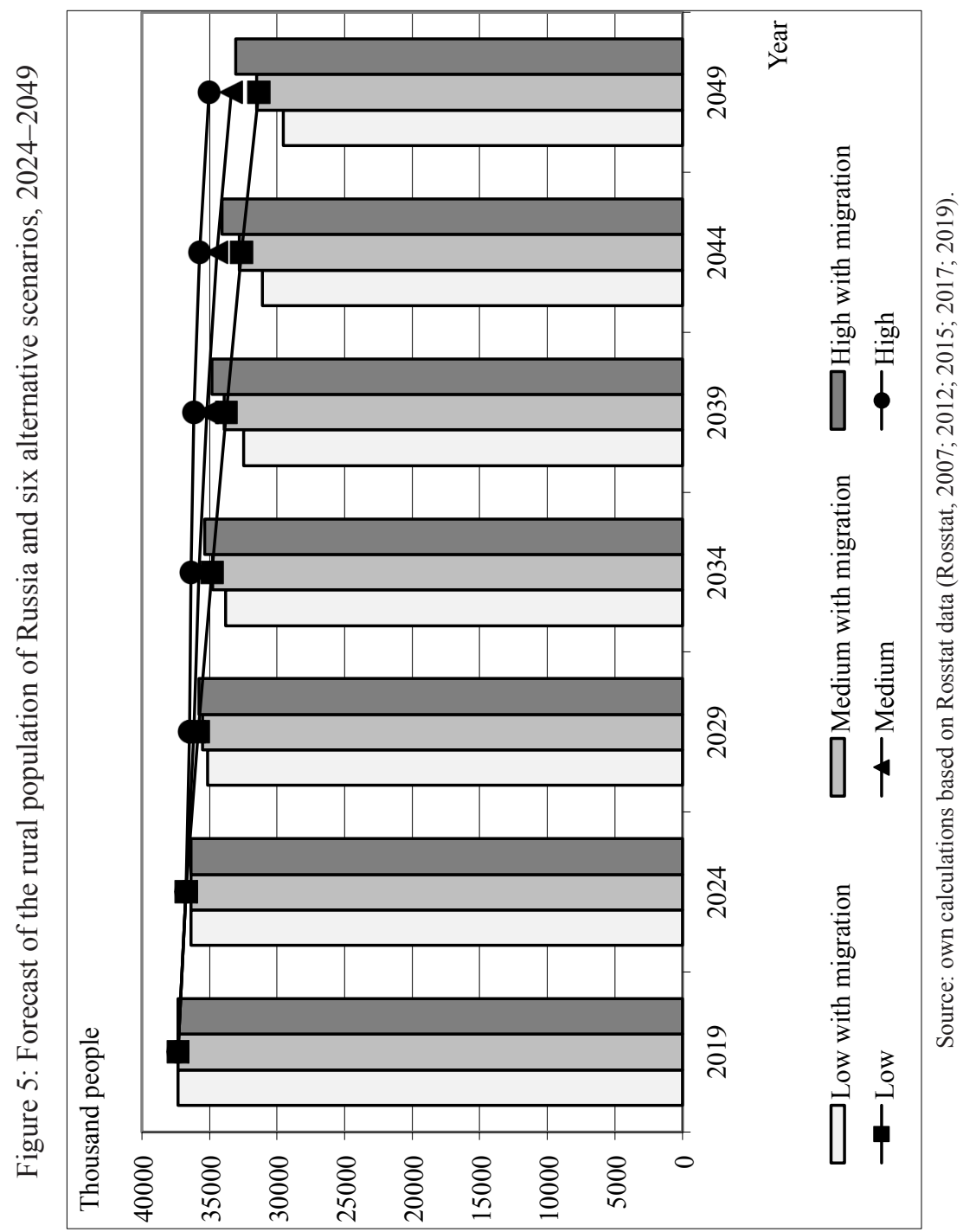


The smallest demographic losses are projected according to the high scenario, which can be considered as "optimistic", simulating the implementation of the target indicators of national projects.

According to the results of this scenario, by 2049, the rural population will decrease by 2.3 million people excluding migration outflow and by 4.3 million people with the migration rate of 2018. The size of the rural population of the Russian Federation according to scenarios with zero migration will be reduced to $35.8-36.5$ million people (2029), to $33.8-36.2$ (2039) and to 31.3-35.0 million people (2049). By 2039, the discrepancy between the "upper" and "lower" borders of the projected rural population will amount to 2.4 million people, and by 2049 it will increase to $3.7 \mathrm{mi}-$ llion people.

\section{Conclusion}

The paper focuses on the demographic forecast and alternative scenarios of the size of rural population (2024-2049). Trends in the demographic development of rural Russia are considered. The forecasting results showed that according to all the considered scenario conditions of demographic development, the size of the rural population of the Russian Federation will decrease, and by the beginning of 2049 it is expected to reach 83.9 per cent to 93.8 per cent of its population in 2019 , excluding the migration outflow. The difference between the "upper" and "lower" boundaries of the estimated rural population by the beginning of 2029 will be 636 thousand people, and by the beginning of 2049 it will grow to 3.7 million people. According to the results of the study, the dynamics of migration processes have a significant impact on the projected size and gender and age composition of the rural population. According to the low version of the forecast, by 2029, the size of the rural population, taking into account migration, is projected to be 1.9 per cent less than without migration, and by 2045 it will be 5.7 per cent less than without migration. Nevertheless, the decrease in the rural population in the high version, taking into account migration by the end of the forecast period, is assumed to be less than in the low scenario without migration. Thus, by 2049, the size of the rural population of the Russian Federation will presumably be in the range of 29.5-33.1 million people if the current level of migration outflow from the rural areas is preserved. 


\section{REFERENCES}

Alho, J., Alders, M., Cruijsen, H., Keilman, N., Nikander, T. and Pham, D.Q., 2006, "New forecast: Population decline postponed in Europe", in Statistical Journal of the United Nations Economic Commission for Europe, 23 (1), 1-10.

Alho, Juha and Spencer, Bruce, 2005, Statistical Demography and Forecasting. Springer, New York.

Anderson, Thomas and Kohler, Hans-Peter, 2015, "Low fertility, socioeconomomic development, and gender equity", in Population and Development Review, 41(3), 381-407.

Blinova, Tatiana, 2021, "Demographic aging of rural areas of Russia", in AIC: Economics, Management, 2, 76-80. DOI: 10.33305/212-76 (in Russ.).

Blinova, Tatiana, Bylina, Svetlana, 2014, "Scenario Forecast of the Number of Rural Population of Russia for the Medium Term", in Economy of region, 4, 298308 (in Rus).

Cafaro, Philip and Dérer, Patricia, 2019, "Policy-based Population Projections for the European Union: A Complementary Approach", in Comparative Population Studies, 44, 171-200.

Denisenko Mikhail, Kozlov Vladimir, 2018, "Generational accounts and demographic dividend in Russia", in Demographic Review. English selection, 40 - 63.

Denisenko Mikhail, Mukomel Vladimir, 2020, "Labour migration in Russia during the coronavirus pandemic, in Demographic Review, 7 (3), 84-107 (in Rus).

Duvander, Ann-Zofie, Lappegard, Trude and Johansson, Mats, 2020, "Impact of a Reform Towards Shared Parental Leave on Continued Fertility in Norway and Sweden", in Population Research and Policy Review, available at: https://doi. org/10.1007/s11113 -020-09574-y.

Frejka, Tomas, 2017, "The Fertility Transition Revisited: A Cohort Perspective". Comparative Population Studies, 42, 89-116.

Gavrilova Natalia, Gavrilov Leonid, 2020, "Patterns of mortality during pandemic: An example of Spanish flu pandemic of 1918", in Population and Economics, 4(2), 56-64. DOI: https://doi.org/10.3897/popecon.4.e53492.

Goujon, Anne, Marois, Guillaume and Sabourin, Patrick, 2020, “Deriving Niger's Demographic and Education Future to 2062 with Stakeholders: Which Results?", in Population Research and Policy Review, available at: https://doi.org/10.1007/ s11113-020-09582-y

Johnson, Kenneth and Lichter, Daniel, 2019, "Rural Depopulation: Growth and Decline Processes over the Past Century", in Rural Sociology, 84 (1), 3-27.

Kulkova Inna, 2020, "The coronavirus pandemic influence on demographic processes in Russia", in Human Progress. vol 6 (1), pp. 1-11. URL: http://progress-human.com/ images/2020/Tom6_1/ Kulkova.pdf. DOI 10.34709/IM.161.5 
Liu, Jun'e, Chai, Lei and Xu, Zina, 2016, "Forecast of China Population under Different Fertility Policy", in Open Journal of Social Sciences, 4, 213-229.

Medalia, Carla and Chang Virginia, 2011, "Gender equality, development, and cross-national sex gaps in life expectancy", in International Journal of Comparative Sociology, 52 (5), 371-89.

Mkrtchyan, Nikita, 2019, "Migration in rural areas of Russia: territorial differences", in Population and Economics, 3 (1), 39-51. https://doi.org/10.3897/popecon. 3.e34780

Ordorica, Manuel, Silvan José Luis y Núñez Juan Manuel, 2019, “Estimaciones de la población desde la tierra como desde el cielo: el caso de Tenosique", in Papeles de Poblacion, 98, 9-29. DOI: http://dx.doi.org/10.22185/24487147.2018.98.34

Petrosian, Artur, Shevchuk, Egor, Kirillov, Pavel, Mozgunov, Nikita, 2019, “Geographical patterns of population aging in Russia", in Demographic Review. English selection, 45-69.

Rindfuss, Ronald, Choe, Minja and Brauner-Otto, Sarah, 2016, "The emergence of two distinct fertility regimes in economically advanced countries", in Population Research and Policy Review, 35(3), 287-304.

Rosstat, 2002, Demographic Yearbook of Russia. 2002, available at: http:/www. gks.ru/bgd/ regl/B02_16/ Main.htm

Rosstat, 2007, Demographic Yearbook of Russia. 2007, available at: http://www. gks.ru/bgd/ regl/B02_16/ Main.htm

Rosstat, 2012, Demographic Yearbook of Russia. 2012, available at: https://www. gks.ru/bgd /regl/B 12_16/Main.htm

Rosstat, 2015, Demographic Yearbook of Russia. 2015, available at: https://www. gks.ru/bgd/ regl/B 15_16/ Main.htm

Rosstat, 2017, Demographic Yearbook of Russia. 2017, available at: http:/www. gks.ru/bgd/regl/B 17_16/ Main.htm

Rosstat, 2019, Demographic Yearbook of Russia. 2019, available at: http://www. gks.ru/bgd/ regl/B19_16/ Main.htm.

Rosstat, 2020, Population of the Russian Federation by sex and age as of January 1, 2020. Federal State Statistics Service, available at: https://gks.ru/bgd/regl/ b20 111/Main.htm

Rybakovsky, Oleg and Tayunova Olga, 2017, "Birth rate of the Russian population and demographic waves", in Population, 4, 56-66 (in Rus).

Rybakovsky, Oleg and Tayunova Olga, 2018, "Labor Migration as the Growth Potential of the Population of Russia", in Population, 4, 59-67 (in Rus).

Ryazantsev Sergey, Ivanova Alla, Arkhangelsky Vladimir, 2021, "Increasing Depopulation in Russia in the Context of the Covid-19 Pandemic: Regional Features", in Bulletin of the South Russian State Technical University (NPI). Series: Socio-Economic Sciences, 2, 7-20 (in Rus). 
Seltzer, Nathan, 2019, "Beyond the Great Recession: Labor Market Polarization and Ongoing Fertility Decline in the United States", in Demography, 56, 4, 1463 93.

Tan, Poh Lin, Morgan, S. Philip and Zagheni, Emilio, 2016, "A case for 'reverse one-child' policies in Japan and South Korea? Examining the link between education costs and lowest-low fertility", in Population Research and Policy Review, 35(3), 327-350.

The Concept of the Demographic Policy of the Russian Federation for the period up to 2025, 2007, Approved by Decree of the President of the Russian Federation of October 9, No 1351, available at: https://base.garant.ru/191961/53f89421bbdaf741eb2d1ecc4ddb 4c33

The National Project "Demography”, available at: http:/government.ru/rugovclassifier/839/ events/

Trynov, Alexander, Kostina, Svetlana and Bannykh, Galina, 2020, "Examination of Socio-economic Determinants of Fertility based on the Regional Panel Data Analysis", in Economy of region, 16 (3), 807-819, https://doi.org/ 10.17059/ekon. reg.2020-3-10 (in Rus).

United Nations, 2019, World Population Prospects, vol. I: Comprehensive Tables. Department of Economic and Social Affairs. New York: United Nations.

Zeman, Kryštof, Beaujouan, Éva, Brzozowska, Zuzanna and Sobotka, Tomáš, 2018, "Cohort fertility decline in low fertility countries: Decomposition using parity progression ratios", in Demographic research, 38 (25), 651-90.

\section{Curricular information of The authors}

\section{Tatiana Viktorovna Blinova}

Doctor of Economics (Saint Petersburg State Economic University, Russia). Full member of Peter academy of sciences and arts (Saint Petersburg), member of Regional Science Association International, expert of Russian Academy of Sciences, expert of Russian Science Foundation. The leader of projects supported by scientific foundations. Author or co-author of over two hundred articles, books and chapters of monographs. Main research area is population, economics and demography, forecasting of social and demographic development, agrarian labor market, modeling of interregional differences in rural unemployment. At present - professor, chief researcher of the Laboratory of social development of agro-industrial complex and rural areas, Institute of Agrarian Problems of RAS.

E-mail: ruandre@mail.ru

ORCID: http://orcid.org/0000-0001-6144-7314 


\section{Svetlana Gennadievna Bylina}

$\mathrm{PhD}$, Economics (Institute of Agrarian Problems of the Russian Academy of Sciences, Saratov, Russia). Main research area is population economics and demography, forecasting of social and demographic development, state regulation of the economy and management of socio-economic processes. Participated in projects supported by scientific foundations (Russian foundation for basic research, Russian science foundation and others). Author of over fifty publications, has gratitude and certificates. At present - senior researcher of the Laboratory of social development of agro-industrial complex and rural areas, Institute of Agrarian Problems of the Russian Academy of Sciences.

E-mail: svbylina@rambler.ru

ORCID: http://orcid.org/0000-0002-5179-7721 